\title{
PENGARUH TURBULENSI TERUMBU BUATAN SILINDER BERONGGA BAGI KESUBURAN PERAIRAN
}

\author{
(THE EFFECT OF TURBULENCE GENERATED BY HOLLOW CYLINDER \\ ARTIFICLAL REEFS)
}

\author{
Rudhy Akhwady ${ }^{1}$ dan Haryo Dwito \\ ${ }^{1}$ Corresponding author \\ E-mail : jtpkipb@gmail.com
}

\begin{abstract}
Plankton as an indicator of abundance was strongly influenced by nutrient availability and the distribution of nutrients. Distribution patterns and the availability of elements around the habitat structure also influenced by the turbulence around the artificial reefs that occured. So, the solution to enhance plankton abundance was by increasing the level of turbulence. This paper reviewed flow pattern around a bollow cylindrical reef, with deployment of artificial reef expected increasing turbulence and amount of plankton amount in the vicinity of artificial reefs. The measurement data showed an progress about intensity of turbulence that occured between the hollows cylindrical reefs and measured in condition any reefs (existing) at least 1.022 and 0.655 in reefs condition. The existence of this artificial reefs were expected to increase plankton abundance and againt plankton to keep moving inward and impassing on artificial reef toward coastal becaused of wave celerity in order to do spawning, nursing and growing safely.
\end{abstract}

Keywords : Plankton, artificial reefs, nutrient, turbulence

\begin{abstract}
ABSTRAK
Plankton sebagai indikator kesuburan perairan sangat dipengaruhi oleh ketersediaan unsur hara dan tingkat sebaran nutriennya. Pola sebaran dan ketersediaan unsur di sekitar habitat struktur juga dipengaruhi oleh adanya turbulensi di sekitar terumbu buatan yang terjadi. Sehingga salah satu cara meningkatkan kesuburan perairan yaitu dengan cara meningkatkan tingkat turbulensinya. Dalam makalah ini akan dikaji model pola aliran di sekitar terumbu buatan berbentuk silinder, diharapkan bentuk terumbu yang diusulkan dapat meningkatkan turbulensi dan jumlah plankton yang tertahan di sekitar terumbu buatan ditempatkan. Hasil pengukuran menunjukkan adanya peningkatan intensitas turbulen di sekitar perairan yang terjadi diantara rongga-rongga terumbu dan diukur pada saat kondisi tanpa terumbu (eksisting) sebesar 1.022 dan terdapat terumbu sebesar 0.655. Diharapkan keberadaan terumbu buatan ini dapat meningkatkan kesuburan perairan dengan menahan aliran plankton agar bergerak ke dalam terumbu sehingga bisa berlindung dan tidak bergerak melewati terumbu menuju pantai. Dengan demikian nantinya di dalam terumbu bisa melakukan pemijahan, perkembangbiakan serta pertumbuhan didalamnya.
\end{abstract}

Kata kunci: Plankton, terumbu buatan, nutrien, turbulen

\section{PENDAhUluan}

Indonesia dengan luas laut 5,8 juta $\mathrm{km}^{2}$ mempunyai potensi kelautan, perikanan dan pariwisata yang sangat besar. Potensi lestari sumberdaya perikanan laut Indonesia sebesar 6.167.940 ton/tahun (Budiharsono, 2001). Tetapi potensi yang besar tersebut akan hilang apabila komponen pendukungnya seperti ekosistem terumbu karang mengalami kerusakan. Menurut Kementerian Lingkungan Hidup (1996) dari luas terumbu karang yang ada di Indonesia sekitar $50.000 \mathrm{~km}^{2}$ diperkirakan hanya $7 \%$ terumbu karang yang kondisinya sangat baik, 33\% baik, $46 \%$ rusak dan 15\% lainnya dalam kondisi kritis (Supriharyono, 2000).

Rusaknya terumbu karang tersebut akan berpengaruh terhadap kelangsungan hidup ikan dan beragam biota laut lainnya. Untuk itu diperlukan suatu upaya pelestarian agar kerusakan terumbu karang dapat dicegah. Salah satu upaya yang dilakukan untuk mengatasi masalah kerusakan terumbu karang tersebut diantaranya dengan transplantasi karang dan teknologi terumbu karang buatan (artificial reeflyang terbuat dari bahan balok beton, potongan kapal, perahu kayu, mobil bekas, dan ban bekas serta bambu.

Dengan melihat keberadaan plankton di suatu perairan sebagai dasar informasi tentang kualitas dan tingkat 
kesuburan perairan, maka di dalam mendesain terumbu buatan perlu meperhatikan beberapa faktor, seperti : cahaya dan unsur hara. Pengaruh cahaya terkait dengan produktifitas sangat kuat, dikarenakan dibutuhkan selama kegiatan fotosintesis berlangsung (Nybakken, 1992 ; Estrada, M dan Berdallet, E, 1997). Pendapat sama juga dikemukan oleh Nontji (2008) karena adanya pengaruh lingkungan dalam kegiatan produksi primer plankton yaitu: cahaya matahari dengan spektrum yang lebar dengan panjang gelombang 400$720 \mathrm{~nm}$, dimana suhu matahari berpengaruh pada perubahan enzimatik proses fotosintesis (makin rendah suhu air maka berat jenis makin tinggi).

Plankton merupakan organisasi komunitas kelompok yang hidup secara kolektif di laut dengan pola melayang, dengan klasifikasi penggolongan plankton terdiri atas : zooplankton (hewani) dan fitoplankton (nabati). Penggolongan plankton dilakukan dengan melihat ukuran yang berhasil di tangkap oleh jaring plankton. Dengan kemampuan fitoplankton mampu berfotosintesis dengan menyerap cahaya matahari, mempunyai ukuran yang lebih besar dari zooplankton serta merupakan tingkatan plankton jenis diatoms dan dinoflagelata. Sedangkan zooplankton merupakan komunitas kelompok hewanhewan planktonik dan berada di wilayah yang terdapat makanan.

Daur kehidupan fitoplankton hidup secara melayang berada di daerah yang cukup cahaya matahari untuk fotosintesis, sedangkan zooplankton hidup di daerah yang mempunyai banyak fitoplankton sebagai sumber makanan. Dari beberapa zooplankton yang hidup tersebut, merupakan sumber makanan bagi ikan yang banyak tersebar di sekeliling terumbu karang pada waktu siang hari. Sedangkan pada malam harinya, ikan-ikan bersembunyi dan mencari makan di sekitar dan di celahcelah terumbu karang.

Dalam perilakunya, aktifitas ikan juga dipengaruhi oleh adanya respons terhadap terumbu karang, atau yang disebut "Reefiness". Beberapa instink kelompok ikan banyak dipengaruhi oleh adanya perbedaan stimulus "Taxis" seperti : Phototaxis (cahaya), Chemotaxis (bau), dll (Nakamura, 1985).
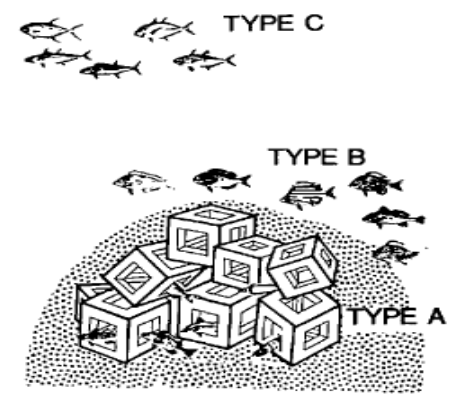

Gambar 1. "Reefiness" sebagai respon ikan ke arah terumbu

(Nakamura, 1985)

Sebagai contoh dari tiga kelompok jenis ikan, adanya jenis ikan A yang lebih menyukai kontak fisik dengan terumbu dan tinggal di tengah lubang/celah terumbu, jenis ini merupakan mayoritas kelompok ikan yang menetap sebagai bentik seperti ikan karang dan ikan kod. Sedang ikan tipe B lebih banyak tinggal di sekitar terumbu buatan karena adanya pengaruh cahaya dan suara, dan sebagian sisanya tinggal di dasar laut. Untuk kelompok jenis ikan tersebut, terumbu karang yang direncanakan mempunyai lubang dengan variasi ukuran tidak lebih besar dari 2 meter, lebar struktur yang dapat menghasilkan pusaran air maksimum di bawah kondisi arus yang ada serta kecepatan arus di bagian dalam tidak melebihi tingkat yang normal sehingga ikan-ikan dapat aman dipersembunyian.

Sedangkan untuk ikan tipe C, lebih banyak menunggu di atas terumbu dan sebagian jenis ini lebih banyak berada di bagian tengah dan atas kolom air. Kaitan antara terumbu dan ketidakstabilan arus, fluktuasi tekanan dan efek suara yang diakibatkan terumbu.

Arus turbulen dapat terjadi dalam perairan, ketika arus air laminar bertabrakan dengan suatu penghalang (barier) seperti terumbu buatan kemudian timbul pusaran (eddies) disekitar penghalang tersebut (Armono, 2010).

Bentuk hubungan antara suplai nutrient dan turbulen terkait terkait dengan tingkat kesuburan perairan digambarkan dalam bentuk sistematisasi fungsi morfologi phytoplankton. Sistematisasi ini dikemukakan oleh Margalef (1978) yang dikenal dengan Margalef's Mandala, seperti pada Gambar 2. 


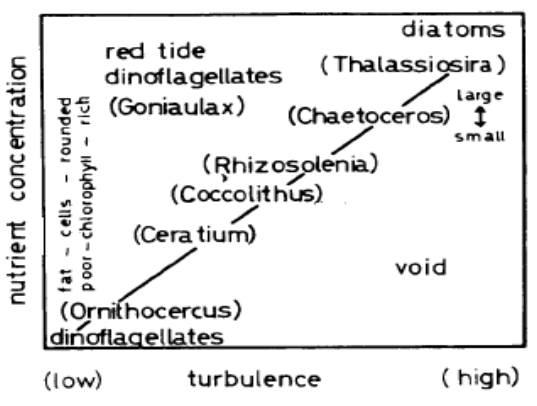

Gambar 2: Pola Kehidupan Fitoplankton (Margalef, 1978)

Kerangka konsep taxonomi Margalef (1978) mengelompokkan fitoplankton ke dalam beberapa wilayah. Jenis diatoms tumbuh dengan subur di perairan yang turbulen dan nutriennya tinggi. Di bawah kondisi ini terdapat dinoflagelata yang bergerak sesuai dengan perubahan kolom air dan dipengaruhi oleh unsur sedimen yang berperan dalam penyediaan gizi.

Beberapa planktologist sendiri juga telah membedakan skala turbulen yang terjadi berkaitan dengan fisiologi fitoplankton dan distribusinya, diantaranya adalah : Yamazaki dan Osborn (1988) yang membagi kedalam tiga skala turbulen : mesoskala (jarak 10 $\mathrm{km}-100 \mathrm{~km}$ ) dengan perubahan gerakan air laut akibat upwelling. Meso skala (beberapa sentimeter) dan fineskala (beberapa meter), gerakan turbulen terjadi dekat permukaan dan di beberapa lapisan air laut akibat gravitasi, konveksi, angin dan instrusi termohaline.

Menurut Kirboe, T (1997), turbulen skala besar akan menaikkan konsentrasi makanan dan ketersediaan makanan bagi predator. Sedang turbulen dalam skala kecil akan meningkatkan transport nutrient ke arah permukaan sel-sel fitoplankton. Ditambahkan juga oleh Mc. Cave (1984) apabila adanya turbulen skala juga dapat meningkatkan partikel tersuspensi bahkan meningkatkan nutrien dengan penguraian partikel yang terjadi.

Sedangkan dengan adanya aliran vertikal turbulen menurut Estrada dan Berdalet (1997) akan menyebabkan adanya pencampuran perubahan penetrasi cahaya dan nutrien sebagai akibat adanya perbedaan kolom air.

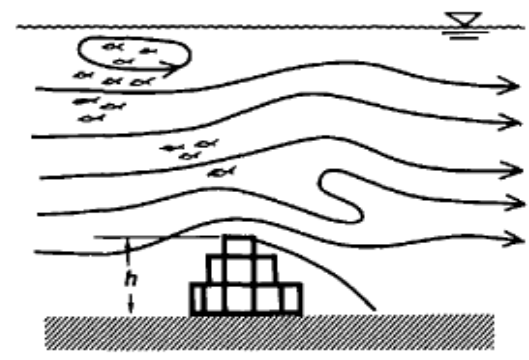

Gambar 3. Gelombang di bagian dalam Terumbu (Nakamura, 1985).

Tingkat perubahan kecepatan turbulen sangat berpengaruh pada karakteristik lingkungan perairan. Menurut Mac Kenzie et al., (1991), turbulen dapat mengurangi tingkat photoadaptive secara vertikal dari populasi plankton karena perbedaan kolom air, dan dengan terjadinya turbulen terjadi proses dispersi populasi plankton akan lebih besar dibanding di daerah yang tenang.

\section{BAHAN DAN METODE}

Lokasi yang dipilih sebagai tempat penempatan terumbu adalah Pantai Putih di Kecamatan Bungatan, Situbondo, Jawa Timur. Dikarenakan lokasi tersebut merupakan salah satu kawasan wisata dan konservasi laut yang mempunyai kekayaan alam berupa terumbu karang dan ikan-ikan hias. Maka dengan kondisi ekologi pantai Pasir Putih yang sekarang ini makin banyak di kunjungi oleh wisatawan baik domestik dan internasional. Karena selain tersebut juga menyediakan aktifitas wisata diving dan snorkling sebagai wisata bawah air. Posisi terumbu berada pada kedalaman 3,2 m dengan koordinat $113^{\circ} 49,42^{\prime} 05 \mathrm{E}$ dan 70 41,30’60 S (Gambar 4).

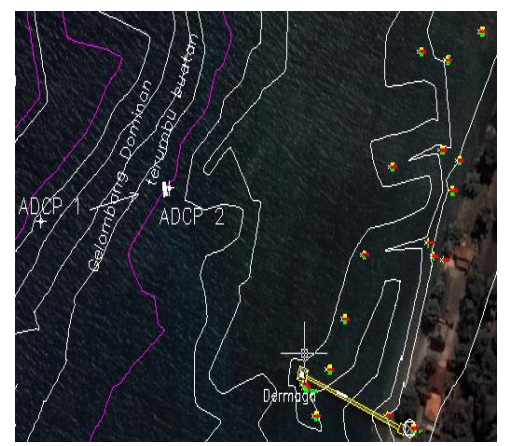

Gambar 4. Lokasi Penempatan Terumbu di Pasir Putih, Situbondo 
Penempatan dan pengukuran parameter fisik dan oseanografi terumbu dilakukan di lapangan pada tanggal 1720 Agustus 2010, dengan tujuan untuk mengetahui tingkat keberhasilan setelah penempatan (deployment). Dari pengukuran yang dilakukan dengan Acoustic Doppler Current Profiler (ADCP) tipe Sontek Argonaut 10-XR diperoleh tinggi gelombang berdasar waktu (jam) pengukuran dalam kurun waktu 12 terlihat bahwa gelombang datang (incident) yang terjadi dilapangan cukup kecil, yaitu berkisar antara $5 \mathrm{sd} 15 \mathrm{~cm}$, dengan periode antara $2-4$ detik.

$$
\text { Menurut Munson (2003), }
$$
intensitas turbulen didefinisikan sebagai akar rata-rata kuadrat kecepatan fluktuatif dibagi dengan kecepatan ratarata menurut fungsi waktu sebagaimana didefinisikan dalam persamaan di bawah ini :

$$
I=\frac{\sqrt{\overline{\left(u^{\prime}\right)^{2}}}}{\bar{u}}=\frac{\left[\frac{1}{T} \int_{t o}^{t o+t}\left(u^{\prime}\right)^{2} d t\right]^{1 / 2}}{\bar{u}}
$$

Dimana : $I=$ Intensitas turbulen, $\mathrm{u}=$ kecepatan turbulen $\mathrm{m} / \mathrm{det}, \bar{u}=$ kecepatan turbulen rata-rata.

Intensitas turbulen pada daerah yang tenang akan lebih kecil nilainya daripada yang tidak tenang, misalnya : intensitas untuk aliran di atmosfer dan sungai nilainya lebih besar dari 0.1 . Sedangkan intensitas dalam terowongan angin memiliki intensitas turbulen antara 0.0002 sampai dengan 0.01 (Munson, 2003). Semakin besar intensitas turbulen, maka fluktuasi kecepatan turbulen juga semakin besar.

\section{HASIL DAN PEMBAHASAN}

Hasil pengukuran arus di sekitar lokasi pengamatan baik pada kondisi dengan maupun tanpa terumbu buatan yang dilakukan secara serentak/ bersamaan pada kedua lokasi diberikan pada Gambar 5 dan 6. Pada Gambar 5 berikut ini ditunjukkan hasil pengukuran pada lokasi dengan terumbu buatan pada posisi sebelum (offshore) dan sesudah terumbu buatan (onshore). Sumbu vertikal kiri menunjukkan bacaan kecepatan arus dalam $\mathrm{cm} /$ detik sedangkan sumbu vertikal kanan menunjukkan arah kecepatan yang dinyatakan dalam derajat. Berturut-turut arah utara dinyatakan dalam 0 atau $360^{\circ}$, Timur $90^{\circ}$, Selatan $180^{\circ}$, dan Barat $270^{\circ}$. Sumbu horizontal menunjukkan waktu pembacaan kecepatan dan arah arus secara bersamaan.

Dari hasil pengukuran di atas tercatat bahwa kecepatan di lokasi setelah terumbu buatan lebih tinggi bila dibandingkan dengan lokasi sebelum terumbu buatan. Demikian pula arah arus saat pengukuran di daerah onshore (pantai) lebih dominan ke arah utara pada awal pengukuran. Selanjutnya pada saat air menuju pasang, arus dari offshore berasal dari arah Selatan. Kecepatan arus juga mengalamai penurunan saat air menuju surut hingga mencapai titik terendahnya dan berangsur-angsur meningkat. Gambar 6 berikut menunjukkan pengukuran di lokasi tanpa terumbu buatan pada posisi offshore (laut lepas) dan onshore (dekat pantai). Seperti halnya Gambar 5 sebelumnya, sumbu vertikal kiri menunjukkan bacaan kecepatan arus dalam $\mathrm{cm} /$ detik sedangkan sumbu vertikal kanan menunjukkan arah kecepatan yang dinyatakan dalam derajat. Berturut-turut arah utara dinyatakan dalam 0 atau $360^{\circ}$, Timur $90^{\circ}$, Selatan $180^{\circ}$, dan Barat $270^{\circ}$. Sumbu horizontal menunjukkan waktu pembacaan kecepatan dan arah arus secara bersamaan.

Pada Gambar 5 nampak jelas pula perubahan arah pergerakan arus dari kondisi pasang menuju surut sebagaimana terlihat pada Gambar 5a. Berbeda dengan kondisi dengan terumbu, kecepatan arus lebih kecil pada lokasi onshore bila dibandingkan dengan lokasi offshore untuk lokasi tanpa terumbu buatan. Kecepatan pada lokasi onshore berkisar antara 0,5 sampai 19 $\mathrm{cm} /$ det sementara kecepatan pada lokasi offshore berkisar antara 1 sampai 50 $\mathrm{cm} /$ det. Secara sepintas nampak bahwa ada penurunan nilai koefisien transmisi hingga $30 \%-20 \%$, sebagaimana terlihat pada gambar 7 , namun hasil pengukuran pada lokasi tanpa terumbu pun menunjukkan nilai Kt hingga 30\%, sehingga belum terlihat secara signifikan kinerja terumbu dalam mereduksi gelombang. Hal ini mungkin disebabkan oleh kecilnya gelombang yang terjadi pada saat pengukuran, (maksimum hanya sebesar $15 \mathrm{~cm}$ ) atau juga karena kekurangpekaan ADCP dalam mengukur tinggi gelombang karena berdasarkan 
sistem pressure sensor, sehingga penempatan ADCP yang terlalu jauh di bawah laut mengurangi tingkat kepekaannya dalam mengukur tinggi gelombang, ditambah lagi tinggi gelombang yang terlalu kecil. Sedangkan gelombang yang melewati terumbu buatan (transmitted) memiliki tinggi geombang yang lebih kecil yaitu antara
2,5 sampai $7,5 \mathrm{~cm}$ dengan periode 8 sampai 10 detik pada daerah tanpa terumbu dan berkisar antara 8 sampai 12 detik pada daerah dengan terumbu (Gambar 8). Data fisik dan oseanografi hasil pengukuran berupa tinggi gelombang dan kecepatan di sekitar terumbu yang dilakukan ditampilkan dalam Tabel 2.

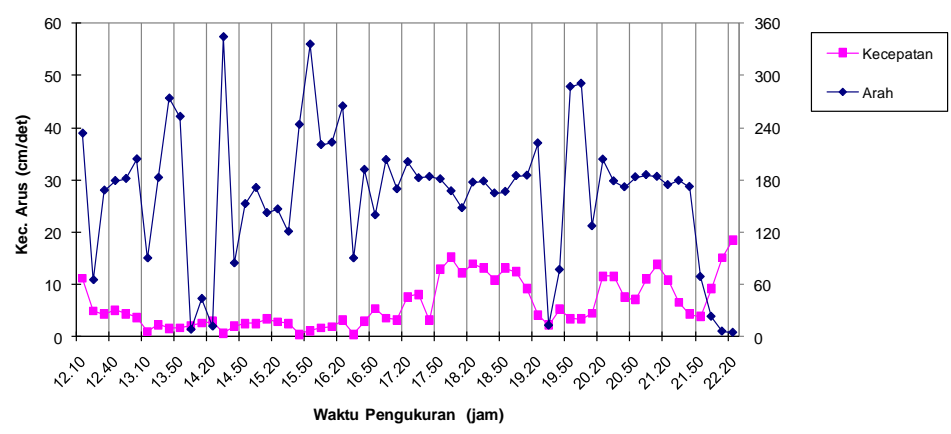

a. Hasil Pengukuran di Offshore

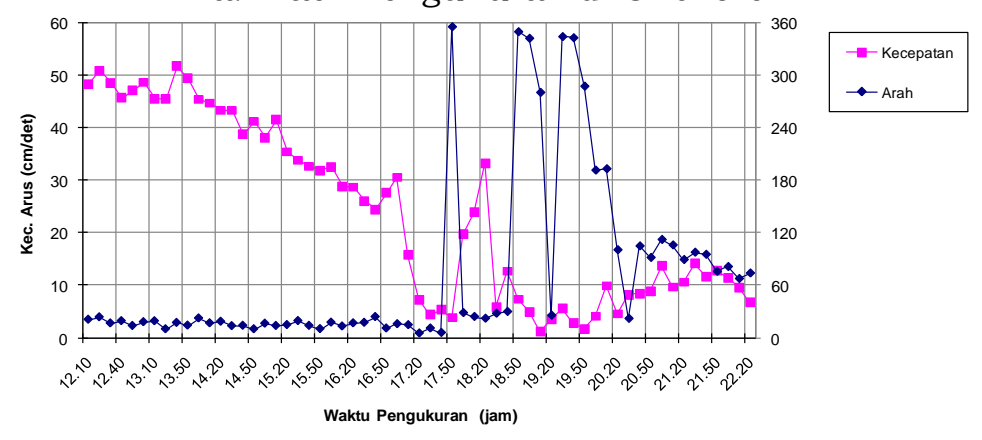

b. Hasil pengukuran di onshore

Gambar 5. Hasil pengukuran kecepatan dan arus di sekitar terumbu buatan (sumber: Laporan Hibah Pasca, 2010)

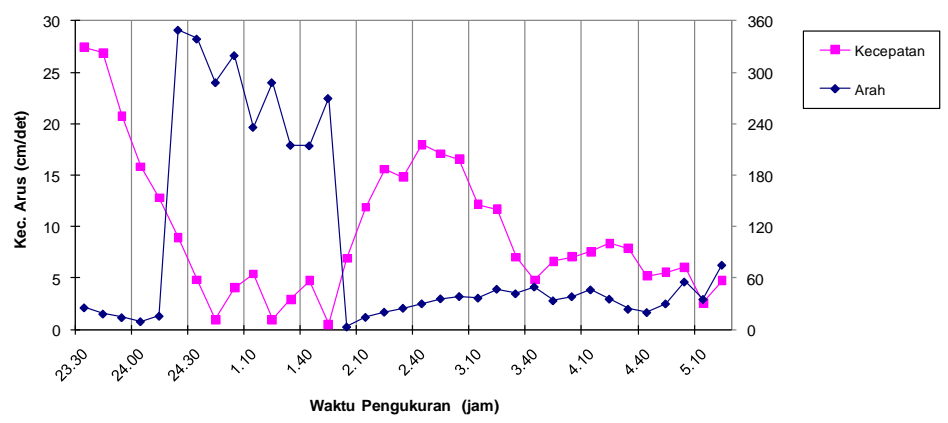

a. Hasil pengukuran tanpa terumbu di offshore 


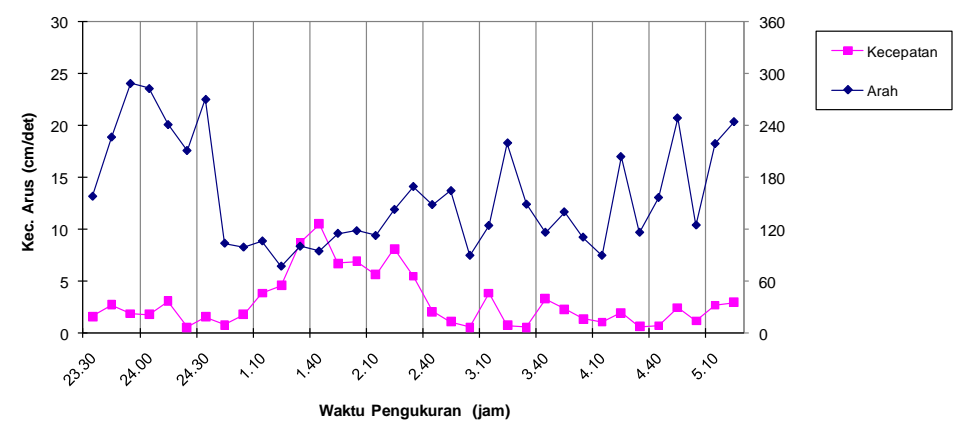

b. Hasil pengukuran tanpa terumbu di onshore

Gambar 6. Hasil pengukuran kecepatan dan arus tanpa terumbu buatan/eksisting (sumber: Laporan Hibah Pasca, 2010)

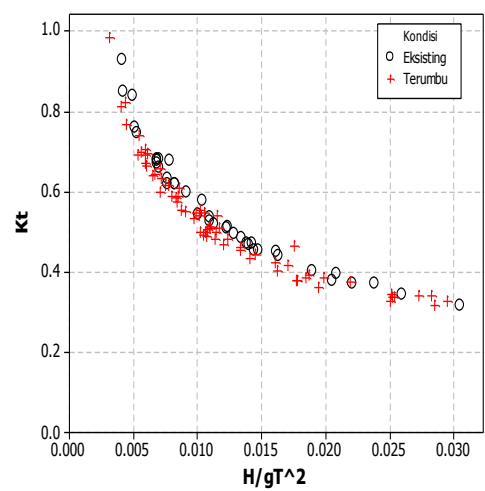

Gambar 7. Perbandingan kecuraman gelombang $(\mathrm{H} / \mathrm{gT} 2)$ dengan koefisien transmisi terumbu terumbu buatan

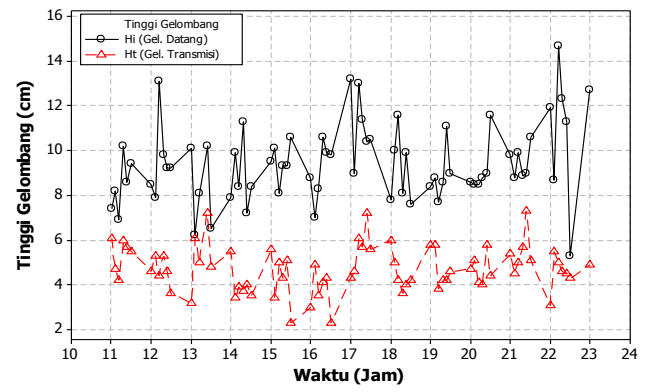

Gambar 8. Hubungan tinggi gelombang dengan waktu

Tabel 2. Hasil pengukuran peredaman bottle reef di Situbondo

\begin{tabular}{|c|l|c|c|}
\hline \multirow{2}{*}{ No. } & \multicolumn{2}{|c|}{$\begin{array}{c}\text { Parameter Fisik } \\
\text { Dan Oseanografi }\end{array}$} & \multicolumn{2}{c|}{ Bottle Reef } \\
\cline { 3 - 4 } & \multicolumn{1}{|c|}{ Incident } & Transmisi \\
\hline 1. & Tinggi Gelombang $(\mathrm{cm})$ & 9.485 & 4.691 \\
2. & Kecepatan Arus $(\mathrm{cm} / \mathrm{dt})$ & 7.446 & 12.923 \\
3. & Periode (detik) & 3.59 & 8.89 \\
4. & Temperatur $\left({ }^{\circ} \mathrm{C}\right)$ & 29.6 & 29.6 \\
5. & Intensitas Turbulensi & 1.021 & 0.665 \\
\hline
\end{tabular}

Sumber : Hasil Pengukuran

Berdasarkan hasil pengukuran yang dilakukan, dapat dinyatakan bahwa dengan tingginya intensitas turbulen yang terjadi zona offshore (wilayah gelombang datang) dibanding zona onshore (wilayah gelombang transmisi) dimana di area ini tinggi gelombang berhasil direduksi menjadi lebih kecil dan menyebabkan tingkat kesuburan berkurang. Sehingga dengan adanya 
perbedaan kesuburan akibat perbedaan intensitas turbulen di sekitar terumbu, maka biota di periaran tersebut menjadikan keberadaan terumbu buatan sebagai zona transisi atau tempat transit (shelter) agar dapat melakukan kegiatan pemijahan, pembesaran dan perkembangbiakan dengan aman.

Sebagaimana beberapa

hasil penelitian tentang hubungan kesuburan dengan turbulensi yang menyebutkan bahwa naiknya konsentrasi transport nutrient makanan akibat dan ketersediaan ke arah permukaan bagi sel-sel fitoplankton (Kirboe, 1997). Dengan adanya turbulen dapat meningkatkan partikel tersuspensi bahkan meningkatkan nutrient (Mc. Cave,1984). Akibat aliran vertikal turbulen menurut menyebabkan adanya pencampuran perubahan penetrasi cahaya dan nutrien sebagai akibat adanya perbedaan kolom air (Estrada dan Berdalet,1997). Tingkat terjadinya turbulen dengan adanya proses dispersi populasi plankton akan lebih besar dibanding di daerah yang tenang (Mac Kenzie et al,1991).

\section{KESIMPULAN}

Hasil penelitian yang dilakukan membuktikan bahwa fungsi terumbu yang terpasang di Pasir Putih, Kab. Situbondo Jawa Timur selain sebagai peredam gelombang juga berfungsi sebagai tempat habitat bagi ekosistem di sekitarnya untuk kegiatan pemijahan, perkembangbiakan dan pembesaran. Zona offshore dengan intensitas turbulensi lebih tinggi sebesar $1.022 \mathrm{di}$ banding zona onshore sebesar 0.665 membuktikan bahwa secara teoritis mempunyai tingkatan supplai nutrient bagi kesuburan perairan yang lebih baik. Sehingga dapat dinyatakan bahwa peran terumbu buatan yang terpasang dapat berfungsi sebagai zona transisi pola aliran yang berfungsi sebagai transitnya habitat (sheltering) bagi biota di perairan tersebut.

Sehingga salah satu upaya untuk meningkatkan potensi ekosistem biota laut di suatu wilayah perairan dapat dilakukan dengan memasang terumbu agar terjadi peningkatan kesuburan suatu perairan yang ditandai dengan meningkatnya jumlah plankton. Upaya ini dapat dilakukan dengan mendesain bentuk terumbu yang selain berfungsi sebagai fish shelter agar dapat meredam gelombang (di zona onshore) dengan cara mereduksi tinggi gelombang datang (incident) menjadi gelombang transmisi (transmitted) sehingga tinggi gelombangnya menjadi lebih rendah. Dengan adanya gelombang transmisi yang lebih kecil menyebabkan kondisi garis pantai tetap terlindung dari serangan gelombang penyebab terjadinya erosi di sepanjang pantai.

\section{Ucapan Terima Kasih}

Ditujukan kepada Dirjen Dikti Kemendiknas yang telah memberikan bantuan dukungan dana Laporan Akhir Hibah Penelitian Tim Pasca SarjanaHPTP(Hibah Pasca) Tahun III(kontrak No: 0172.0/023-04.2/XV/2010), sehingga penelitian ini dapat dilaksanakan sesuai dengan yang direncanakan.

\section{DAFTAR PUSTAKA}

Anonimous, (2010),"Laporan Akhir Hibah Penelitian Tim Pasca Sarjana-HPTP (Hibah Pasca) Tahun III". ITS Surabaya.

Budiharsono S., (2001)., “Teknik Analisis Pembangunan Wilayah Pesisir dan Lautan", Pradnya Paramita. Jakarta.

Bengen, D, (2001), “ Ekosistem dan Sumber Daya Pesisir Laut Serta Pengelolaan Secara Terpadu dan Berkelanjutan", Prosiding Pelatihan Pengelolaan Wilayah Pesisir Terpadu, PKSPL IPB.

Bleck, M and Omeraci, H. (2001). "Wave Damping and Spectral Evolution at Art Reef". Proceedings 4th International Symphosium on Ocean Wave Measurement and Analysis. San Francisco, California, USA.

Estrada, M and Berdalet, E . (1997)." Phytoplankton in a Turbulent World". SCI. MAR., 61 (Supl. 1): 125-140.

Fachrul, M.F. (2005) “ Komunitas Phytoplankton Sebagai Bioindikator Kualitas Perairan Teluk Jakarta", Seminar Nasioanal FMIPA UI.

Ilyas, M., (2000). Studi Awal Penerapan Teknologi Terumbu Karang Buatan di Sekitar Kepulauan Seribu, Jurnal Sains dan Teknologi 
Indonesia, V2. n7, Oktober 2000, hal. 46-52 /Humas-BPPT/ANY.

Kirboe, T. (1997). "Small-scale Turbulence, Marine Snow Formation, and Planktivorous Feeding”. Sci. Mar., 61 (Supl. 1): 141-158.

Margalef, R. (1978), "Life-Forms of Fitoplankton Survival Alternatives in an Unstable Environment Oceanol, Acta, 1:493-509.

Matsuda, S et al (2003). "Crown Height Effects on Stability of Flat Type Concrete Armor Blocks". Proceedings of The Thirteenth, International Offshore and Polar Engineering Conference. Honolulu, Hawaii, USA.

Mc. Cave. IN, (1984). "Size Spectra and Aggregation of Suspended Particles in the Deep Ocean". Deep Sea Res., 31:329-352.
MacKenzie, et al (1991). "Quantifying the Contribution of Small-Scale Turbulence to the encounter Rates Between Larval fish and their Zooplankton prey : effects of Wind and Tide ". Marine Ecology Progress Series.73:149-160.

Munson, B.R, et al. (2003). Fundamentals of Fluid Mechanic 2" John Wiley \& Son, Inc. USA.

Nakamura, M. (1985). "Evaluation of Artificial Fishing Ref. Concepts in Japan". Bulettin of Marine Science, 37(1):271-278.

Nontji. A. (2008), “ Plankton Laut”. LIPI Press, Jakarta.

Munson, B.R, et al. (2003). "Fundamentals of Fluid Mechanic 2" John Wiley \& Son, Inc. USA.

Supriharyono, (2000)., "Pelestarian dan Pengelolaan Sumber Daya Alam di Wilayah Pesisir Tropis", Gramedia Pustaka Utama. Jakarta. 